\title{
all about TOS PEOPLE
}

DURING A RECENT staff meeting at the office, a colleague commented that 2005 was an especially challenging and frustrating year for the ocean sciences community. I believe this was a valid observation, especially if one were a researcher seeking funding support during a period of flat or decreasing federal budgets, or for the many people in the ocean community who were impacted by the disastrous hurricanes this past season. But for The Oceanography Society (TOS), it was a good year. This positive assessment comes from considering how well TOS fulfilled expectations of its membership and met its basic mission. This success is all about TOS people.

A highlight of the year was the launching of the Fellowship Program. An important function of a professional society is to recognize and honor individuals who have made important scientific and societal contributions. In 2005, TOS recognized the first group of TOS Fellows, who were honored during the 2006 Ocean Sciences meeting in Honolulu. TOS Fellows are nominated and elected on the basis of their contributions towards the goals of the society. TOS was established to be an integrating factor for the field of oceanography and to advance oceanography as a true scientific discipline. This goal involves bringing together and recognizing individuals from all fields of oceanography, representing the diverse interests of members in research, engineering, industry, policy, and education.

The main criteria for being elected a TOS Fellow are outstanding and sustained contributions, and devotion to the broad field of oceanography, commensurate with the founding principles of the Society. The 2005 TOS Fellows are:

- John Cullen for fundamental contributions to our understanding of the influence of environmental conditions on phytoplankton function in the ocean.

- Bob Duce for research on the global biogeochemistry of trace elements in the ocean/atmosphere system.

- Peggy Delaney for paleoceanographic research in nutrient and carbon cycling and service to the oceanographic and scientific ocean drilling communities.

- Michael McPhaden for El Niño-Southern Oscillation (ENSO) research and unselfish service in providing the community with tropical atmosphere and ocean observations (TAO array).

Congratulations to the inaugural class of TOS Fellows!

In addition to the Fellows, TOS honored a member of the ocean science community by conferring The Walter Munk Award to Peter Worcester. This award is granted jointly by TOS, the Office of Naval Research, and the Office of the Oceanographer of the Navy in recognition of distinguished research in oceanography, towards understanding physical ocean processes related to sound in the sea, and the application of acoustic methods to that understanding. The award was presented during a plenary session at the 2006 Ocean Sciences meeting. Peter's citation reads:

In recognition of his early and continuing contributions to the development of acoustical oceanography and tomographic inverse methods for acoustic measurement of ocean processes, for tireless service aimed at developing a responsible permitting structure for the use of sound in the sea for scientific purposes, and for leadership in the U.S. ocean acoustics community. 
Although their contributions have less visibility than do those of the TOS Fellows and Munk Awardees, members of the TOS Council deserve recognition. The TOS Council functions as the Board of Directors and as such is the principal governing body of the Society. It consists of the elected officers (President, PresidentElect, and the immediate Past-President), and at least six other elected voting members of the Society, each elected for a three-year term. One-third of the councilors rotate off each year. At its June 2005 meeting, the Council elected to add a seventh councilor position for education and outreach.

The 2005 TOS elections had the largest slate of candidates and the largest number of votes cast in the Society's history. Three new council members were elected: Susan Lozier, Duke University, succeeding Lynne Talley for Physical Oceanography; Mary Jane Perry, University of Maine, succeeding Curt Davis for Biological Oceanography; and Gisèle Muller-Parker, Western Washington University, as the new Education and Outreach councilor. Welcome aboard, and thank you Lynne and Curt for your past service to TOS.

By all measures, the Society's flagship publication, Oceanography, had a remarkable year. The special issue on women in oceanography was widely acclaimed and is by far the most requested issue that TOS has published. All four issues published in 2005 were exceptionally well edited and produced. In working with guest editors, Ellen Kappel, Nancy Caputo, and Johanna Adams do a fantastic job for the society in publishing this journal. And the useful brochure Scientifically Speaking describing the do's and don'ts of preparing scientific talks and posters has been updated and republished. Thank you Mark Abbott and Ann Gargett for updating this best seller-available free of charge on the TOS web site (http://www.tos.org).

Scientific conferences were another 2005 highlight for TOS. The June 2005 International Ocean Research Conference in Paris (co-sponsored by TOS and UNESCO) covered a wide spectrum of topics that ranged from genomics to paleoclimate reconstructions. The goal of the conference was to reflect on how far oceanography has come and to discuss the coming decade of international collaboration in science and education. Oscar Schofield, Catherine Jeandel, and Elizabeth Gross put in many hours of thought and hard work to make the conference the outstanding success that it was. In addition, Chuck Trees contributed great wisdom and effort on behalf of TOS as its program co-chair for both the 2004 joint meeting with ASLO and the 2006 joint meeting with AGU and ASLO. Chuck's contributions to the success of these meetings required a great deal of patience and negotiating skills. On behalf of all the TOS membership who attended these events, thank you!

And keeping rein over the entire enterprise is Jenny Ramarui, the TOS Executive Director. Jenny, with the part-time help of a bookkeeper, does it all—from responding to members' questions and requests via phone calls and emails, to writing proposals to support dedicated issues of the magazine, to making logistical arrangements for meetings, to keeping the accounting records to very high standards. Her role is part ringleader, part den mother, and chief advocate for the Society. TOS benefits from her caring and goodnatured attitude.

TOS runs on a wealth of time, talent, and expertise of its members. However, it also runs on a financial shoestring. Membership dues and voluntary contributions are the primary source of unrestricted funds to maintain the Society's operation. I hope that TOS has a strong future, continuing the success of 2005. With your sustained help and support, it certainly can.

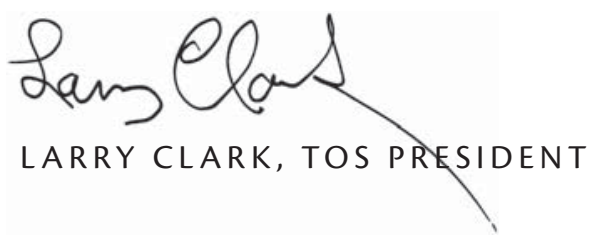

